American Journal of Economics and Business Administration 3 (3): 534-542, 2011

ISSN 1945-5488

(C) 2011 Science Publications

\title{
Organizational Citizenship Behavior (OCB) amongthe Managers of Teaching Hospitals
}

\author{
${ }^{1}$ Fereshteh Farzianpour, ${ }^{2}$ Abbas Rahimi Foroushani, \\ ${ }^{3}$ Hossein Kamjoo and ${ }^{4}$ Sayed Shahab Hosseini \\ ${ }^{1}$ Department of Health Management and Economics, \\ ${ }^{2}$ Department Epidemiology and Statistic, \\ ${ }^{1,2}$ School of Public Health, Tehran University of Medical Sciences, Tehran \\ ${ }^{3}$ Hospital of Shahid Sadoughi, University of Medical Sciences and Health Services, Yazd \\ ${ }^{4}$ Department of Management, Tehran University, International Campus-Kish Island
}

\begin{abstract}
Problem statement: Organizational behavior is desirable for any organization, as it is associated with important organizational variables such as job satisfaction, organizational productivity and system maintenance. The main purpose of this study is to evaluate the mean organizational behavior score among the managers of the hospitals affiliated to Shahid Sadoughi University of Medical Sciences and Health Services, Yazd. Approach: A descriptive-analytic cross-sectional study was conducted on 117 managers in various organizational levels working at the study hospitals who were randomly selected. questionnaire was used which validity and reliability are approved by the university management professors and Cronbach's alpha coefficient of 0.70, respectively. All the questions were presented in a Likert scale with five options measuring four dimensions: (A) Generosity (B) Civil behavior (C) Conscious (3 D) Friendship. The data were entered in the SPSS software and Fisher exact test and chi-square test were used for data analysis. Results: The mean age of the study population is 39 years among whom $66.7 \%$ were male and $33.3 \%$ were female. The working experience of the study population was averagely 15.6 years. A total of 78 (66.7\%) managers are educated in medicine, allied medicine and basic sciences. Considering the scores in different components of organizational behavior, generosity was placed first with a mean score of 12.3 and conscious was placed fourth with a mean score of 5.47. Conclusion: There was statistically significant association between sex, education level and the field of study and being placed in certain quartiles of OCBs domains $(\mathrm{p}<0.05)$.
\end{abstract}

Key words: Organizational citizenship behavior, OCBs domains, Civil behavior, data analysis, organizational variables, allied medicine, hospitals affiliated, system maintenance

\section{INTRODUCTION}

Organizational behavior is desirable for any organization, as it is associated with important organizational variables such as job satisfaction, organizational productivity and system maintenance (Farzianpour et al., 2011a; Kwantes et al., 2008). The studies show that the managers can develop organizational behavior by establishing or improving a positive working environment instead of resorting to force and control, relying on the processes of selection, employment or socialization (Farzianpour et al, 2011b; Kamdar et al., 2006).

Along with outspreading of customer orientation campaign and the emergence of new aspects in the
Management Studies, the concept of organizational behavior is also considered in the organization related studies; organizational attitudes and behaviors of the employees can have positive or negative impact on the customer perception of the quality of the services (Yaffe et al., 2011; Farzianpour et al., 2011a).

The vital forces of a service organization are its employee, especially the forefront personnels who are directly dealt with the customer (Eric et al., 2010). Unlike the products, the services are produced and consumed simultaneously and the forefront service personnels are essentially the service producers (Robinson and Morrison, 2006). This aspect of services has led to too much focus on the vital role of the service personnel in the distribution of high quality services (Nielsen et al., 2009).

Corresponding Author:Fereshteh Farzianpour, Department of Health Management and Economics, School of Public Health, Tehran University of Medical Sciences, Tehran 
In fact, as the "customer dealing personnels" are the organization service providers, they directly affect the customer satisfaction and play a marketing role (Podsakoff et al., 2010). In fact, they perform the marketing functions. They can properly perform these functions, which profit the organization, which will be considered as an advantage for the organization or can be poor providers of these functions are which is not beneficial to the organization (Organ et al., 2006). Indeed, a certain set of behaviors by the staffs that interact and are directly dealt with the costumers during service delivery can have a significant impact on the customer perception of the service quality, especially the voluntary behaviors that the personnel administer both for the customer and the organization (Todd and Kent, 2006).

One of the major research areas in organizational behavior studies is identifying the dimensions of organizational behavior. Strong evidences support the impact of organizational behaviors on the effectiveness of organizational and team work (Bove et al., 2009). Organizational behavior is beneficial in managing the dependencies between the members in a working unit resulting in increased access to team results (Guenzi and Georges, 2007).

Today, a wide variety of experimental and conceptual links exist regarding the relationship between organizational performance and the effectiveness of the organizations. The researches in the field of performance have shown that most or parts of the personality tend to better predict the performance than the duties performance; hence, use of Personality Assessment probably leads to selection of the individuals who meet some competencies and qualifications. Most of the attention and interest to the category of Organizational Citizenship Behavior (OCB) has occurred in the past fifteen years (Gonzalez and Garazo, 2006).

Organizational behavior has many benefits: OCB is of little importance in terms of individual profits; however, it benefits both the organization and the personnel based on various approaches (Haque et al., 2011).

Considering the interests of the organization, the organizational behavior leads to having a group of personnel who are committed to the organization. According to Daniel (2010), OCB alone (especially dedication, loyalty and tolerance) reduces the personnel absenteeism and desertion and the staff who are committed to the company remain with the company for a long time and produce high quality products and help the company's position using various approaches. We can logically guess that the organizational behavior may promote a better working environment within the organization (Haque et al., 2011; Wanxian and Weiwu, 2007; Korkmaz and Arpaci, 2009; Ingham, 2008).
The fundamental issue in the present study is that what strengths and weakness points exist in the country's governmental organizations, especially hospitals which have much more contact with the society compared with other government agencies, considering the various components of organizational behavior and what are the priorities of the organization for maintaining these types of behaviors.

In order to respond to this concern and fundamental issue, we have tried to identify the strengths and weaknesses of the managers of the hospitals affiliated to Shahid Sadoughi University of Medical Sciences and Health Services, Yazd, in organizational behaviors and to provide essential strategies to achieve the desirable status, as well (Farzianpour et al, 2011b).

Conceptual framework of organizational citizenship

behavior: Although the term "organizational citizenship behavior" was first introduced by Bateman and Organ (1983), this concept origins from the writings of Barnard (1938) about cooperation tendency and the studies by Katz and Kahn, 1966; Katz, 1964) about performance and spontaneous behaviors beyond the expectations of the role (Bateman and Organ, 1983; Katz, 1964; Katz and Kahn, 1966., Alpha and Vincent, 2011). However after the introduction of this concept by Organ different experts have clarified this issue over two decades using concepts such as Extra-role Behavior, Prosocial Organizational Behavior, Organizational Spontaneity and Contextual Performance (VanDyne et al., 1995).

Generally, those behaviors are most considered in OCB that although for which there is no obligations by the organization, if administered by the personnel, provide benefits for the organization (Korkmaz and Arpaci, 2009). Organ has defined OCBs as behaviors under individual control which although are not explicitly and directly considered by the formal reward systems, enhance the effectiveness of the organization performance (VanDyne et al., 1995).

Types of organizational citizenship behavior: Despite the growing attention to the issue of citizenship behavior, an overview of the literature in this field shows the lack of consensus about the dimensions of this concept. The literatures indicate that thirty different types of citizenship behavior are identifiable with various definitions among which there are a lot of overlaps. The number of studies which are currently investigating the issue is dramatically on the rise; however, there is no general consensus on the various dimensions of OCB.

Organ (1988) provided a multidimensional scale of organizational citizenship behavior. This scale is composed of five dimensions which form the structure of OCB; these five dimensions of OCB include: 
Altruism: To help the colleagues and staffs to cope with their organizationally relevant task or problem in uncommon circumstances.

Conscientiousness: performing the assigned tasks in a manner beyond what is expected.

Sportsmanship: emphasis on the positive aspects of the organization rather than the negative aspects.

Civic virtue: encompasses supporting the administrative operations of the organization.

Courtesy: Consulting with others before acting, informing before actions and information exchange (Organ, 1988).

Altruism, courtesy, conscientiousness, civic virtue and sportsmanship.

Podsakoff et al. (2000) has provided a detailed classification of such behaviors dividing OCBs in seven categories:

- Helping behaviors

- Sportsmanship

- Personal innovation

- Civic virtue

- Organizational commitment

- Self-satisfaction

- Personal development (Podsakoff et al., 2000)

Markoczy and Katherine (2004) divide organizational citizenship behavior into two types:

- Positive and active assistance

- Avoiding the behaviors that can hurt the colleagues and the organization

Citizenship actions includes activities that include helping others do their tasks, supporting the organization and volunteering in doing accessory tasks or taking responsibility (Markoczy and Katherine, 2004).

Borman and Motowidlo (1993), to specifically explain the actions of organizational citizenship offered a five-dimensional model, including:

- Perseverance combined with enthusiasm and extraordinary efforts which are necessary to successfully complete the work activities

- To volunteer for performing work activities which are not formally a part of the individuals tasks

- Assistance and cooperation with others

- Following the rules and practices of the organization

- To support, protect and defend the organization's goals (Borman and Motowidlo, 1993)
Markoczy et al. (2004) studied organizational citizenship behavior according to the cultural conditions in China in the following format:

- Social customs,

- Altruism,

- Working conscious,

- Interpersonal mutual coordination,

- Protecting organizational resources (Markoczy and Katherine, 2004)

Natmyer and Colleagues (1997) also divide OCBs into four categories (Natmyer et al. 1997):

- Generosity

- Civil behavior (Social customs)

- Conscious

- Friendship

\section{MATERIALS AND METHODS}

The study was conducted using descriptive-analytic cross-sectional method. The study population consisted of all hospital managers at various levels (including internal manager, matron, supervisor, ward director, head nurse, service manager and financial manager) among which 117 individuals were randomly selected. The main objective was to estimate the average organizational behavior score for which no study have been done on hospital managers in Iran. Thus, the number of samples was estimated based on this score range which vary between 10 and 60 ; considering the standard deviation for organizational behavior as 10 and the average difference between estimated and actual score to be 1.5 in maximum, the sample size was calculated for $95 \%$ confidence interval as 178 using the following formula:

$$
\begin{aligned}
& \mathrm{N}=\left(\mathrm{z}^{2} * \sigma^{2}\right) / \mathrm{d}^{2} \\
& \mathrm{~N}=\frac{(1.96)^{2 *}(10)^{2}}{(1.5)^{2}}=178
\end{aligned}
$$

Given that the total population of managers in the hospitals of Yazd province is 279 people which make up a limited population, the sample size was adjusted and calculated as follows:

$$
\begin{aligned}
& \frac{178}{178}=110 \quad \frac{110}{13}=9 \\
& --- \\
& 1+279 \\
& 9 * 13=117
\end{aligned}
$$


In order to select these 110 managers, the list of the hospitals in Yazd province which are 13 hospitals and the number of managers was provided and then, as the number of managers in the hospital was equal, the total number of 110 was divided by 13 and 9 mangers were randomly selected from each hospital. However, 117 managers were finally selected. Natmyer (1997) questionnaire was used as the data collecting tool which validity and reliability were approved by the university management professors and Cronbach's alpha coefficient of 0.70 , respectively. All the questions were presented in a Likert scale with five options measuring four dimensions:

- Generosity (3 items the questions 1,2 and 3)

- Civil behavior (3 items the questions 4, 5 and 6)

- Conscious (3 items the questions 7, 8 and 9)

- Friendship (3 items the questions 10,11 and 12)

Besides, the questionnaire response rate was $100 \%$.

The data were entered in the SPSS software version 17.00 and Fisher exact test and chi-square test were used for data analysis.

The ethical considerations for agreeing to work in hospital settings was approved by taking recommendation from the University Health Deputy and the hospital's senior executives cooperation.

\section{RESULTS}

The mean age of the study population was $39 \pm 7.7$ who were categorized into three age groups of less than 35 years ( 40 cases $-34.2 \%$ ), between 35 45 years (46 patients-39.3\%) and more than 45 years (31 cases-26.5\%). Among these cases, there were 78 males (66.7\%) and 39 females (33.3\%). Among the samples 110 were married (94\%) and the rest were single or divorced. The subjects' average working experience was $15.64 \pm 8.5$ which was in the fields of technical, administrative, financial or service context; $78(66.7 \%)$ were educated in the fields of medicine, allied health and basic sciences. From the study group, $76(65 \%)$ had a supervisor position and $28(23.9 \%)$ were working as the department chairman or other positions. The mean working experience of the individuals in the current position was $8.27 \pm 7.06$ (Table 1). The mean score in the domain of generosity was $12.30 \pm 2.31$, in the domain of civil behavior was $6.32 \pm 1.934$, in the domain of conscious was $5.47 \pm 1.942$ and in the domain of friendship was $6.01 \pm 1.744$ (Table 2). Thus, in terms of the scores for different domains, generosity was placed first and conscious was placed fourth (Table 2 ). The Table 3 shows that there was no statistically significant association between age and being placed in certain quartiles of OCBs domains (P-value = 0.605 ). Table 4 shows that there was a significant association between the OCBs domains of the managers and their education level and also their organizational position $(\mathrm{p}=0.061, \mathrm{p}=0.005$, respectively). Table 5 shows the results for the regression model consisting of the variables of study field and hospital type and the dependent variables of generosity, conscious, friendship and organizational behavior. The managers educated in the technical, financial, administrative or service fields had a higher OCB score $(\mathrm{OR}=2.11)$ compared with the individuals educated in medicine or allied health; however, regarding the upper and lower limits of the scores, this issue was not statistically significant. For the managers working in general hospitals, the score of generosity was higher than those working in single-specialty hospitals; the difference was statistically significant. According to the regression model studying the association between the variables of sex, education, study field and marital status with the dependent variable of conscious score:

The score of the managers with education level less than bachelor is 1.3 times the other group; however, this difference is not statistically significant. Friendship behaviors among the managers educated in the fields of medicine, allied health and basic sciences was less than those educated the financial, administrative or technical fields; the friendship score of the second group is 1.9 times the first group; however, this difference was not statistically significant. The regression model consisting of the variables of sex, education and study field, with the dependent variable of organizational behavior dimensions indicated that inappropriate organizational behavior was more prevalent among the managers educated in the fields of medicine, allied health and basic sciences compared with those educated the financial, administrative or technical fields. In other words, appropriate organizational behavior was 0.3 times the first group; however, this difference was not statistically significant:

- Inappropriate organizational behavior is more among the women than men. In other words, appropriate organizational behavior in men is 1.8 times the women; however, this difference is not statistically significant

- Inappropriate organizational behavior among those with education level over bachelor is more than the managers with education level below bachelor. In other words, appropriate organizational behavior of those with education level below bachelor is 4.5 times the other group; however, this difference is not statistically significant but is remarkable 
Am. J. of Economics and Business Administration 3 (3): 534-542, 2011

Table 1: Characteristics of managers hospitals of Shahid Sadoughi University of Medical Sciences and Health Services, Yazd (2010)

\begin{tabular}{llll}
\hline Sex & $\mathrm{N}(\%)$ & Experience & $\mathrm{N}(\%)$ \\
\hline Female & $39(33.3)$ & & Education \\
Male & $78(66.7)$ & Diploma & $25(21.4)$ \\
Total & $100(117)$ & Total & $92(78.6)$ \\
& & Employment status & $100(117)$ \\
Married & $7(6.0)$ & Official & $83(70.9)$ \\
Total & $100(117)$ & Contractual & $12(10.3)$ \\
Experience & & Bespoke & \\
Less than 10 years & $31(26.5)$ & Total & $100(117)$ \\
10 to 20 years & $43(36.8)$ & Field, Education & $39(33.3)$ \\
More than 20 years & $43(36.8)$ & Technical, financial, administrative, service & $78(66.7)$ \\
Total & $100(117)$ & Medical and paramedical & $100(117)$ \\
Hospital position & & Total & \\
Service & $36(30.8)$ & Hospital position & $67(57.3)$ \\
Financial & $20(17.1)$ & Expert & $50(42.7)$ \\
Medical and paramedical & $61(52.1)$ & Other & $100(117)$ \\
Total & $100(117)$ & Total & \\
Managerial experience & & Managers studied depending on the type of hospital & $36(30.8)$ \\
Less than 10 years & $76(65.0)$ & Teaching & $63(53.8)$ \\
10-20 years & $28(23.9)$ & General & $18(15.4)$ \\
More than 20 years & $13(11.1)$ & Single-specialty \\
Total & $100(117)$ & & \\
\hline
\end{tabular}

Table 2: The mean and standard deviation score in the domains OCB of managers Hospitals of Shahid Sadoughi University of Medical Sciences and Health Services, Yazd (2010)

\begin{tabular}{lrl}
\hline Domain & $\mathrm{X}$ & $\mathrm{SD}$ \\
\hline Generosity & 12.30 & 2.031 \\
Civil behavior & 6.32 & 1.934 \\
Conscious & 5.47 & 1.941 \\
Friendship & 6.01 & 1.744 \\
\hline
\end{tabular}

Table 3: Distribution of frequency age groups and quartile of all domains of OCB of managers in Hospitals of Shahid Sadoughi University of Medical Sciences and Health Services, Yazd 2010

\begin{tabular}{lllll}
\hline \multicolumn{5}{c}{ Quartile of all domains of OCB of managers } \\
& \multicolumn{5}{c}{ Between the } \\
& Below the & first and & Above the \\
& first quartile third quartile & third quartile & \\
Age groups & $\mathrm{N}(\%)$ & $\mathrm{N}(\%)$ & $\mathrm{N}(\%)$ & Total \\
\hline Under 35 years & $10(25)$ & $18(45)$ & $12(30)$ & $40(100)$ \\
Between 35-45 years & $15(32.6)$ & $18(39.1)$ & $13(28.3)$ & $46(100)$ \\
Over 45 years & $5(16.1)$ & $16(51.6)$ & $10(32.3)$ & $31(100)$ \\
Total & $30(25.6)$ & $52(44.4)$ & $35(29.9)$ & $117(100)$ \\
\hline
\end{tabular}

Chi-sq=2.724, $\mathrm{DF}=4, \mathrm{P}=0.605$

Table 4: Domains of OCB of managers

\begin{tabular}{|c|c|c|c|}
\hline Characteristics of managers & $\mathrm{X} 2$ & DF & $\mathrm{p}$ \\
\hline Age groups & 2.724 & 40.605 & \\
\hline Experience & 1.672 & 40.796 & \\
\hline Sex & 6.907 & 20.320 & \\
\hline Education & 10.595 & 20.005 & \\
\hline Employment Status & 0.565 & 10.728 & \\
\hline Type of responsibility & 7.018 & 40.135 & \\
\hline Hospital position & 5.598 & 20.061 & \\
\hline Position & 2.489 & 10.141 & \\
\hline Type of Hospital & 7.582 & 40.108 & \\
\hline
\end{tabular}

Table 5: Regression variables affect the Domains of OCB of managers in Hospitals of Shahid Sadoughi University of Medical Sciences and Health Services, Yazd (2010)

\begin{tabular}{|c|c|c|c|c|c|}
\hline \multirow[b]{2}{*}{ Domains of OCB } & \multirow[b]{2}{*}{$\begin{array}{l}\text { Regression } \\
\text { Coefficient } \\
\text { (RC) }\end{array}$} & \multirow[b]{2}{*}{$\begin{array}{l}\text { Standard } \\
\text { Deviation } \\
\text { (SD) }\end{array}$} & \multirow[b]{2}{*}{ (OR) } & \multicolumn{2}{|l|}{ (CI) } \\
\hline & & & & $\begin{array}{l}\text { Lower of } \\
\text { limits }\end{array}$ & $\begin{array}{l}\text { Upper of } \\
\text { limits }\end{array}$ \\
\hline Sex & 0.085 & 0.516 & 1.089 & 0.396 & 2.993 \\
\hline Education & 1.516 & 0.858 & 4.555 & 0.847 & 24.503 \\
\hline $\begin{array}{l}\text { Field education } \\
\text { Generosity }\end{array}$ & -1.004 & 0.831 & 0.366 & 0.072 & 1.867 \\
\hline $\begin{array}{l}\text { Field education } \\
\text { Technical, financial, } \\
\text { administrative, service }\end{array}$ & 0.749 & 0.493 & 2.115 & 0.805 & 5.556 \\
\hline Teaching hospital & -1.183 & 0.623 & 0.306 & 0.090 & 1.040 \\
\hline $\begin{array}{l}\text { General hospital } \\
\text { Conscious }\end{array}$ & -1360.000 & 0.573 & 0.257 & 0.0830 & 0.790 \\
\hline Sex & 0.678 & 0.474 & 1.970 & 0.778 & 4.991 \\
\hline AEducation & 0.315 & 0.724 & 1.37 & 0.331 & 5.661 \\
\hline Field education & -0.532 & 0.659 & 0.587 & 0.161 & 2.137 \\
\hline $\begin{array}{l}\text { Married } \\
\text { Friendship }\end{array}$ & 1.982 & 1.122 & 7.258 & -804 & 65.495 \\
\hline Field education & 0.678 & 0.474 & 1.970 & 0.778 & 4.991 \\
\hline Hospital position & 0.315 & 0.724 & 1.370 & 0.331 & 5.661 \\
\hline Married & -0.532 & 0.659 & 0.587 & 0.161 & 2.137 \\
\hline
\end{tabular}

\section{DISCUSSION}

This study aimed to study the organizational behavior of the managers of the hospitals affiliated to Shahid Sadoughi University of Medical Sciences and Health Services, Yazd. In other words, the study question was if there is any association between OCB and the demographic variables of hospital managers and how the status of four components of organizational behavior (1. generosity, 2 civil behavior, 3. conscious and 4. friendship), their importance and their priority are in order to provide a comprehensive program of development and training for the managers. 
Generosity component: Generosity demonstrates behaviors of the personnel tolerating the organization present condition that is lower than the minimum level without any complaint. These behaviors affect the quality of services due to the following reasons:

- An employee with high generosity morality has a positive attitude towards the organization and avoids unnecessary blames and complaints. This type of behavior creates a positive atmosphere among employees resulting in more cooperation and coordination in order to provide better services. It is clear that the employee who is always complaining of the organization situation would never think of upgrading the quality of the services

- Presence of positive working atmosphere in the organization makes a pleasant environment for the customers. It must be noted that the absence of these types of behaviors damages the group cohesion and leads to loss of the atmosphere of friendship and intimate (Haque et al., 2011)

This study showed that generous behaviors is slightly more prevalent among the managers working in general hospitals compared with those working in single-specialty hospitals and the difference was statistically significant. Besides, the generous behaviors is slightly more common among the managers working in teaching hospitals compared with those working in single-specialty hospitals; however, this difference was not statistically significant.

Hence, the type of hospitals affects OCBs. Probably in the single-specialty hospitals, admitting just one type of patients such as psychiatric or burn patients influences OCB. In a study by Samira Ali Rezai during 2009, entitled as Citizenship Behaviors, from the Perspective of Public Hospital Staffs of Tehran University of Medical Sciences it was shown that the employee paid more attention to the component of generosity; the results of the mentioned study is compatible with our results (Farzianpour et al, 2011a). In a literature review, by using a pattern named Albert Moorman, Organ, Niehoff, (Organ et al., 2006). They introduced six factors as the most important ones influencing organizational citizenship behaviors of the employees and managers; these six factors included: altruism, conscientiousness, loyalty, respect, tolerance and generosity.

Conscious component: Conscious and conscientiousness include the voluntary behaviors, more than the minimum requirements of one's role, an employee establishes in the organization such as contacting the office after work time to inquire the organization conditions. The studies have shown that the people who are committed to these types of behaviors try to be on time, have less free-time at work and to fulfill the assigned duties in the best possible way resulting in better performing the organizational duties and ultimately improved performance which will be also manifested at the level of service quality and customer satisfaction (Robinson and Morrison, 2006).

In this study, the component of conscious was confirmed from the perspective of the managers; however, this component had no significant association with sex, education, study field and marital status.

Organizational citizenship behaviors from theory to practice tried to, besides expressing the problem and its importance, to review the literature about OCBs. The result of statistical analysis of the data also shows that the demographic variables have no significant association with OCBs, so that none of the demographic variables (gender, age, work experience) are associated with the improving or deteriorating process of the OCBs. This means that regardless of any age, gender, education, work experience, etc. ranges, entrepreneurial organizational culture can be enhanced in an integrated format without considering these components (Allahyari, 2009; Chegini,2009). The results of this study are compatible with our results.

Friendship component: Friendship means helping other members of the organization in their organizational duties such as helping colleagues with high load of tasks (Robinson and Morrison, 2006: Netemeyer et al., 1997). These behaviors affect the quality of the services for several reasons. First: the services will reach the highest quality when the organization employees consider each other as the customers of the organization and help each other in the organizational tasks with great interest and willingness. Secondly, as stated by podsakoff et al., 2000; AbdulWahab, 2008) when an experienced employee in the organization helps the less experienced staff in solving the problems related to the organization services and train them for efficient ways of delivering services to the customers, this leads to significant improve in the service quality perceived by the customers. Third: friendship creates a positive integrated atmosphere among the organization employee which will appear in the interactions between the employees and the customers. The component of friendship was confirmed from the perspective of the studied managers; however, this component had no significant association with study field, organizational position and marital status. 
Civil behavior component: Civil behavior refers to the responsible participation of the staff and their sense of concern about and sincere interest in social life the organization such as attending the meetings in which their presence is not necessary, however, he feels that this attendance is beneficial to him and the organization (O'Brien and Allen, 2008; Jamilah, 2010). These types of behaviors influence the quality of the services in several indirect ways:

- Civic virtue includes appropriate recommendations on improving the services and the organizational effectiveness. Because the forefront staff of the organizations who are in direct contact with the customers, are the best people who have enough information about development of the organization new services, controlling the organization previous services and improving the quality of the organization existing services

- Another form of civic virtue, which certainly is voluntary participation of the individuals in the organization meetings leads to more coordination between the organization activities, creating team spirit, gaining more experience in how to provide services, reduced barriers for providing quality services to the customers and improved service quality (O'Brien and Allen, 2008). The component of civil behavior is approved in the perspective of the study managers; however, this component was not associated with the variables of age, gender, field of study, organizational position and work experience, types of responsibility, marital status and type of hospital. Khalid and Ali (2005) in a study entitled as the effects of organizational citizenship behavior on deviant behaviors concluded that organizational citizenship behavior is negatively related with deviant behaviors. In the study, the employees delay and absence were considered as the most important deviant behaviors (Khalid and Ali, 2005). According to Khalid and Ali (2005) deviant behaviors are the behaviors the employees apply to avoid working or refuse performing their duties. The results of the study showed that tolerance and civil partnership had the most negative association with deviant behaviors. Besides, conscientiousness has a negative relationship with voluntary absenteeism (Khalid and Ali, 2005)

\section{CONCLUSION}

OCB can be predicted by characteristics of positive personality, positive attitudes, motivation and positive organizational characteristics such as organizational support and work related justice.
Organizational justice, organizational commitment and job satisfaction have positive relationship with leadership behavior in organizations.

The routine job, job conflict, role ambiguity, bureaucratic organizational culture and competition between colleagues have a negative relationship with OCB.

\section{REFERENCES}

Abdul-Wahab, S. A., 2008. A preliminary investigation into the environmental awareness of the omani public and their willingness to protect the environment. Am. J. Environ. Sci., 4: 39-49. DOI: $10.3844 /$ ajessp.2008.39.49

Allahyari, M.S., 2009. Reorganization of agricultural extension toward green agriculture. Am. J. Agric. Biol. Sci., $\quad 4$ : 105-109. DOI: 10.3844/ajabssp.2009.105.109

Alpha, A. and S. Vincent, 2011. Strategy execution: An empirical analysis of obstacles faced by master of business administration executive students. Am. J. Econ. Bus. Admin., 3: 511-524. DOI: 10.3844/ajebasp.2011.511.524

Barnard, C.I., 1938. The functions of the executive. $1^{\text {st }}$ Edn., Harvard University Press, Cambridge, pp: 334.

Bateman, T.S. and D.W. Organ, 1983. Job satisfaction and the good soldier: the relationship between affect and employee "Citizenship". Acad. Manage. J., 26: 587-595.

Borman, W.C. and S.J. Motowidlo, 1993. Expanding the Criterion Domain to Include Elements of Contextual Performance. In: Personnel Selection In Organizations. Schmitt, N. and W. Borman, (Eds.). Jossey Bass, New York, ISBN: 1555424759, pp: 71-98.

Bove, L.L. S.J. Pervan, S.E. Beatty and E. Shiu, 2009. Service worker role in encouraging customer organizational citizenship behaviors. J. Bus. Res., 62: 698-705. DOI: 10.1016/j.jbusres.2008.07.003

Chegini, M.G., 2009. The relationship between organizational justice and organizational citizenship behavior. Am. J. Econ. Bus. Admin., 1: 173-176. DOI: 10.3844/ajebasp.2009.173.176.

Daniel, G.B., E. Sundstrom and T.R. Halfhill, 2010. Utility of OCB: Organizational citizenship behavior and group performance in a resource allocation framework. J. Manag. Jom., DOI: 10.1177/0149206309356326

Farzianpour, F., $\quad$ A.R. Fouroshani, R.G. Vahidi, M. Arab and A. Mohamadi, 2011a. Investigating the relationship between organizational social capital and service quality in teaching hospitals. Am. J. Econ. Bus. Admin., 3: 425-429. DOI: 10.3844/ajebasp.2011.425.429 
Farzianpour, F., S. Aghababa, B. Delgoshaei and M. Haghgoo, 2011b. Performance evaluation a teaching hospital affiliated to Tehran University of medical sciences based on baldrige excellence model. Am. J. Econ. Bus. Admin., 3: 277-281. DOI: 10.3844/ajebasp.2011.272.276

Gonzalez, J.V. and T.G. Garazo, 2006. Structural relationships between organizational service orientation, contact employee job satisfaction and citizenship behavior. Int. J. Service Indus. Manage., $\quad$ 17: 23-50. DOI: $10.1108 / 09564230610651561$

Guenzi, P., C. Pardo and L. Georges, 2007. Relational selling strategy and key account managers' relational behaviors: An exploratory study. Ind. Marketing Manage., 36: 121-133. DOI: 10.1016/j.indmarman.2005.03.014

Haque, A., A. Khatibi and K. Karim, 2011. Reorganization impact on the telekom Malaysia's international division productivity. J. Soc. Sci., 1: 226-231. DOI: 10.3844/jssp.2005.226.231

Ingham, K.M., 2008. Citizenship, support and fit: Exploring the generalizability of these concepts to the occupational domain. ProQuest, Japan, ISBN: 0549706046, pp: 201.

Jamilah, O., M.S.H. Azril, U. Jegak, M. Asiah and A.N. Azman et al., 2010. Can quality of work life affect work performance among government agriculture extension officers? A case from malaysia. J. Soc. Sci., 6: 64-73. DOI: 10.3844/jssp.2010.64.73

Kamdar, D., D.J. McAllister and D.B. Turban, 2006. "All in a day's work": How follower individual differences and justice perceptions predict OCB role definitions and behavior. J. Applied Psycho., 91: 841-855. PMID: 16834509

Katz, D. and R.L. Kahn, 1966. The Social Psycho of Organizations. 2nd Edn., Wiley, New York, pp: 498.

Katz, D., 1964. The motivational basis of organizational behavior. Behav. Sci., 9: 131-146. DOI: $10.1002 / b s .3830090206$

Khalid, S.A. and H. Ali, 2005. The effects of organizational citizenship behavior on withdrawal behavior. Int. J. Manage. Entrepreneurship, 1: 30-40.

Korkmaz, T. and E. Arpaci, 2009. Relationship of organizational citizenship behavior with emotional intelligence. Procedia Soc. Behav. Sci., 1: 24322435. DOI: 10.1016/j.sbspro.2009.01.428
Kwantes, C.T., C.M. Karam, B.C.H. Kuo and S. Towson, 2008. Culture's influence on the perception of OCB as in-role or extra-role. Int. J. Intercul. Relat., 32: 229-243. DOI: 10.1016/j.ijintrel.2008.01.007

Netemeyer, R.G., J.S. Bowles, D.O. MacKee and R. McMurrian, 1997. An investigation into the antecedents of organizational citizenship behaviors in a personal selling context. J. Market., 61: 85-98.

Nielsen, T.M., D.G. Bachrach, E. Sundstrom and T.R. Halfhill, 2010. Utility of OCB: Organizational citizenship: Behavior and group performance in a resource allocation framework. J. Manag. DOI: 10.1177/0149206309356326

Nielsen, T.M., G.A. Hrivnak and M. Shaw, 2009. Organizational citizenship behavior and performance: A meta-analysis of group-level research. Small Group Res., 40: 555-577. DOI: 10.1177/1046496409339630

O'Brien, K.E. and T.D. Allen, 2008. The relative importance of correlates of organizational citizenship behavior and counterproductive work behavior using multiple sources of data. Human performance. 21: 62-88. DOI: $10.1080 / 08959280701522189$

Organ, D.W., P.M. Podsakoff and S.P. MacKenzie 2006. Organizational Citizenship Behavior: Its Nature, Antecedents and Consequences. $1^{\text {st }}$ Edn., Sage Publications, Thousand Oaks, Calif., ISBN: 0761929959, pp: 350.

Podsakoff, N.P., S.W. Whiting, P.M. Podsakoff and P. Mishra, 2010. Effects of organizational citizenship behaviors on selection decisions in employment interviews. J. Applied Psychol., 96: 310-326. DOI: 10.1037/a0020948

Podsakoff, P.M., S.B. Mackenzie, J.B. Pain and D.G. Bachrach, 2000. Organizational citizenship behaviors: A critical review of the theoretical and empirical literature and suggestions for future research. J. Manage., 26: 513- 563. DOi: 10.1177/014920630002600307

Robinson, L.R. and E.W. Morrison, 2006. Psychological contracts and OCB: The effect of unfulfilled obligations on civic virtue behavior. J. Organ. Behav., 16: 289-298 DOI: 10.1002/job.4030160309

Todd, S.Y. and A. Kent, 2006. Direct and indirect effects of task characteristics on organizational citizenship behavior. North Am. J. Psychol., 8: 253-268. 
VanDyne, L., L.L. Cummings and J.M. Parks, 1995. Extra-role behaviors-in pursuit of construct and definitional clarity (a bridge over muddied waters). Res. Organizational Behavior, 17: 215-285.

Wanxian, L. and W. Weiwu, 2007. A demographic study on citizenship behavior as in-role orientation. Personality Individual Differences, 42: 225-234. DOI: 10.1016/j.paid.2006.06.014
Yaffe, T. and R. Kark, 2011. Leading by example: The case of leader OCB. J. Applied Psychol., 96: 806826. DOI: $10.1037 / \mathrm{a} 0022464$ 